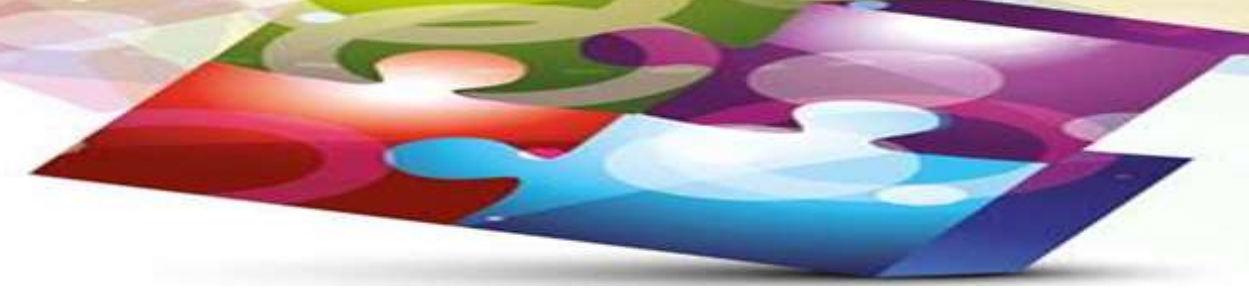

\title{
O TRABALHO DOCENTE E O LICENCIADO EM COMPUTAÇÃO
}

\section{LAS LABORES DE ENSEÑANZA Y EL LICENCIATARIO COMPUTER}

\author{
Claudia Regina Tinós PEVIANI ${ }^{1}$ \\ Maria Cristina Lima PANIAGO²
}

Resumo: O trabalho docente é um tema recorrente nas pesquisas em Educação. Termos como identidade profissional, profissionalização, profissionalidade e valorização profissional são amplamente utilizados nas discussões e reflexões sobre o desenvolvimento do trabalho docente. O objetivo deste artigo é refletir sobre trabalho docente do Licenciado em Computação nos ambientes escolares. Por meio da reflexão teórica, a metodologia utilizada foi a revisão bibliográfica baseado nas leituras de artigos, capítulos de livros e alguns documentos referentes ao curso de Licenciatura em Computação. O Licenciado em Computação é um profissional com formação docente que lhe permite exercer suas habilidades e competências em ambientes escolares e não escolares, todavia os espaços escolares por eles ocupados ainda são muito escassos ou ocupados por outros docentes de outras áreas de conhecimento.

Palavras-chave: Trabalho docente. Desenvolvimento profissional. Licenciado em Computação.

Resumen: El trabajo docente es un tema recurrente en la investigación educativa. Términos como identidad profesional, profesionalización, profesionalismo y valorización profesional son ampliamente utilizados en discusiones y reflexiones sobre el desarrollo de la labor docente. El propósito de este artículo es reflexionar sobre la labor docente del Licenciado en Informática en entornos escolares. A través de la reflexión teórica, la metodología utilizada fue una revisión bibliográfica basada en lecturas de artículos, capítulos de libros y algunos documentos relacionados con la asignatura de Informática. El Licenciatario Informático es un profesional con formación docente que le permite ejercitar sus habilidades y competencias en entornos escolares y no escolares, sin embargo los espacios escolares que ocupan son aún muy escasos o ocupados por otros docentes de otras áreas del conocimiento.

Palabras-clave: Trabajo docente. Desarrollo profesional. Licenciada en Informática.

\footnotetext{
${ }^{1}$ Mestre em Computação (UFMS). Doutoranda do Programa de Pós-Graduação em Educação - Mestrado e Doutorado da Universidade Católica Dom Bosco (UCDB), Campo Grande, MS - Brasil, e-mail: tpeviani@gmail.com.

${ }^{2}$ Professora Doutora, do Programa de Pós-Graduação em Educação - Mestrado e Doutorado da Universidade Católica Dom Bosco (UCDB), Campo Grande, MS - Brasil, e-mail: cristina@ucdb.br.
} 


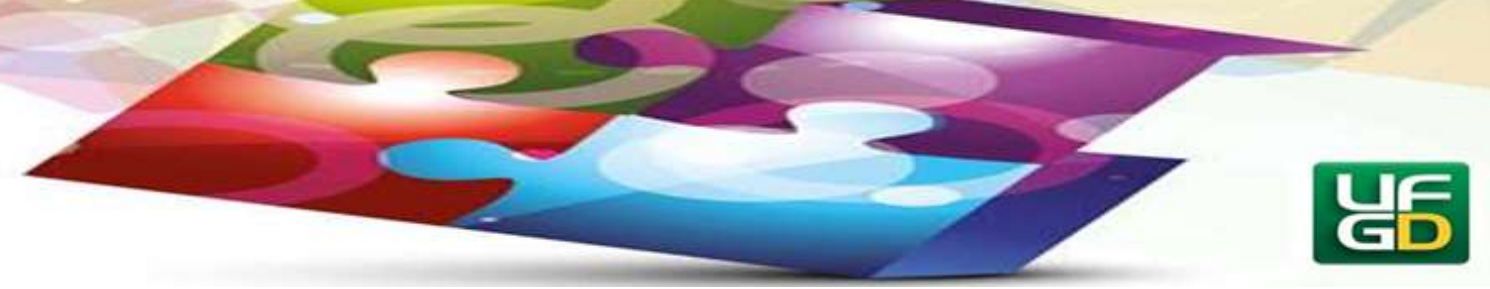

\section{Introdução}

O trabalho docente é um tema recorrente nas pesquisas em Educação. Termos como identidade profissional, profissionalização, profissionalidade e valorização profissional são amplamente utilizados nas discussões e reflexões sobre o desenvolvimento do trabalho docente. Há uma crise na docência com a baixa procura nos vestibulares pelos cursos de licenciatura, o jovem não tem motivação e/ou incentivos para ingressar numa formação profissional para exercer a docência. (DINIZ-PEREIRA, 2011).

Refletir sobre o desenvolvimento do trabalho docente na contemporaneidade é trazer temas como a resistência dos professores na inserção das tecnologias educacionais como recursos pedagógicos, a precarização do trabalho docente em cursos de $\mathrm{EaD}$, as interferências de organizações internacionais nas avaliações de larga escala, o mal-estar e o adoecimento dos professores. Esses temas e outros mais fazem parte dessa reflexão.

O curso de Licenciatura em Computação (LC) é um curso pouco conhecido comparado as outras licenciaturas e é um campo de pesquisa interessante e curioso, principalmente por não haver no currículo da Educação Básica disciplinas da área de Computação como temos Matemática, História, Ciências, Geografia, entre outras. Discutir sobre o desenvolvimento do trabalho docente deste profissional nos possibilita divulgar suas potencialidades nos ambientes escolares

O objetivo deste artigo é refletir sobre o trabalho docente do licenciado em Computação nos ambientes escolares. Trata-se de uma reflexão teórica, a metodologia utilizada foi a revisão bibliográfica baseado nas leituras feitas de artigos, capítulos de livros e alguns documentos referentes ao curso de LC.

Este artigo está organizado da seguinte forma: A Docência e o desenvolvimento profissional, $\mathrm{O}$ trabalho docente na contemporaneidade e $\mathrm{O}$ trabalho docente do Licenciado em Computação.

\section{A Docência e o desenvolvimento profissional}




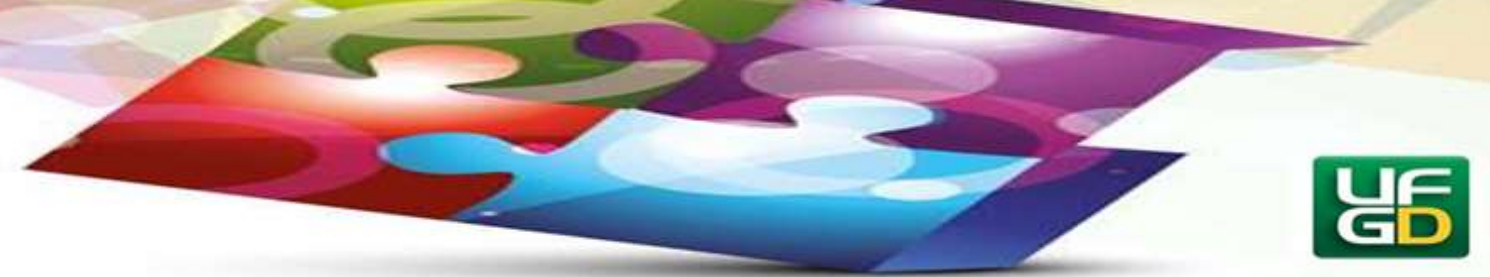

Quando falamos de docência nem sempre pensamos no sentido formal da palavra. Segundo Veiga:

No sentido formal, a docência é o trabalho dos professores; na realidade, estes desempenham um conjunto de funções que ultrapassam a tarefa de ministrar aulas. As funções formativas convencionais, como ter um bom conhecimento sobre a disciplina e sobre como explicá-la, foram tornando-se mais complexas com o tempo e com o surgimento de novas condições de trabalho (VEIGA, 2008, p. 13).

De acordo com Veiga (2008, p. 13) “[...] a docência é o trabalho dos professores”, sendo assim a docência pode ser vista como uma profissão. Como sendo uma profissão perpassa pela remuneração, plano de carreira, condições de trabalho e também pela formação inicial e continuada.

Um tema que está em constante debate no cenário educacional brasileiro é a valorização docente. Desde a década de 1980 houve uma desvalorização da atividade profissional docente. Dando início as "[...] primeiras greves de professores das escolas públicas e privadas, desencadeando um movimento de luta por melhores salários e melhores condições do trabalho docente" (DINIZ-PEREIRA, 2011, p. 37). De acordo com Diniz-Pereira há uma crise da profissão docente no Brasil que reflete nas Instituições de Ensino Superior (IES) públicas e privadas pela baixa procura por cursos de licenciaturas.

Oliveira (2013) aponta dados impressionantes sobre o interesse dos jovens que concluíram o Ensino Médio e que desejam continuar os estudos na busca por uma profissão:

Em estudo realizado pelo Instituto Nacional de Estudos e Pesquisas Educacionais (Inep), denominado "Quem quer ser professor no Brasil? O que o Enem nos diz", com jovens de 17 a 20 anos que fizeram a prova do Exame Nacional do Ensino Médio - Enem em 2007, observou-se que 25\% ainda não haviam escolhido, até aquele momento, a profissão que pretendiam seguir. Dos que já haviam feito sua escolha, a maioria optou por profissões da área de Ciências Biológicas e da Saúde, seguidas por profissões da área de Engenharias e Ciências Tecnológicas e da área de Ciências Humanas. Aqueles que escolheram a profissão de Professor da Educação Básica correspondem a apenas 5,2\% dos jovens (OLIVEIRA, 2013, p. 53).

Por meio dessa informação é perceptível a crise da profissão docente. Os jovens estão procurando profissão de "maior prestígio". Para Diniz-Pereira a identidade docente está:

[...] fortemente marcada por um sentimento de inferioridade, mediocridade e incapacidade. As políticas públicas educacionais têm grande responsabilidade na construção e perpetuação desse significado, uma vez que a valorização do 


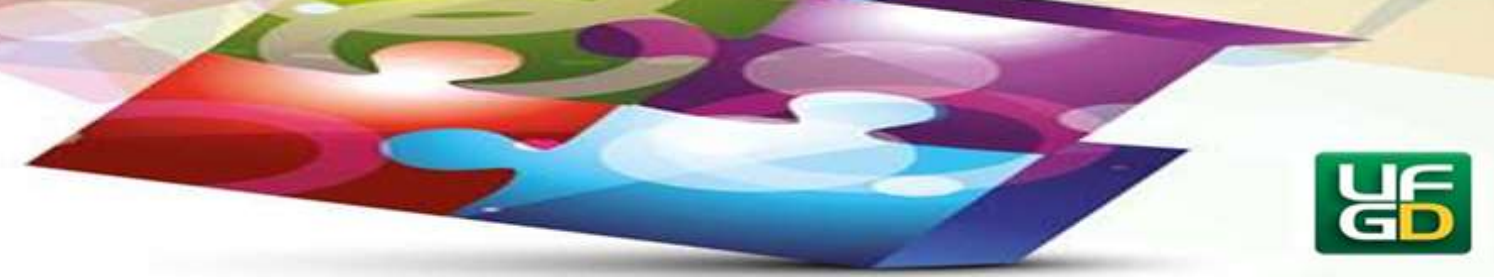

profissional da educação não consegue ir além de um discurso demagógico, que não se traduz em melhorias efetivas nas condições salariais e de trabalho dos professores (DINIZ-PEREIRA, 2011, p. 47).

Outro fator apontado por Oliveira (2013) diz respeito a formação inicial, há ainda um número considerável de docentes que estão atuando na educação básica sem a habilitação específica. Nesse sentido, o governo federal juntamente com os Estados e municípios traçaram metas a fim de sanar esse problema por meio do avanço da Educação a Distância (EaD). As políticas para a formação docente no Brasil por meio da EaD aumentaram consideravelmente a quantidade de cursos de licenciaturas. Vejamos os dados expostos por Oliveira (2013):

Segundo a Associação Brasileira de Educação a Distância (Abed), a melhoria na titulação dos professores brasileiros foi içada por outro fenômeno educacional recente: a expansão da educação à distância (EAD) no país. Entre 2000 e 2008, a quantidade de alunos nessa modalidade, em cursos de graduação e pós-graduação lato-sensu, cresceu $45.000 \%$, passando de 1.758 para 786.718 matriculados. No mesmo período, o número de cursos reconhecidos pelo Ministério da Educação aumentou de 13 para 1.752 (OLIVEIRA, 2013, p. 58).

Alguns pesquisadores questionam a qualidade do ensino na modalidade a distância, principalmente devido à mercantilização existente em algumas instituições privadas. Mas o fato é que por meio da $\mathrm{EaD}$ está sendo possível aumentar o número de docentes com formação inicial. Muitos são os desafios enfrentados para seu desenvolvimento profissional, todavia sua identidade profissional já se inicia quando ele se coloca como professor e seus pares o reconhece como tal. No exercício da profissão docente um sentimento de pertencimento surge e o desenvolvimento profissional se dá mediante a troca de experiência com os colegas, no planejamento compartilhado, na resolução de problemas em conjunto com a direção, coordenação e outros docentes, no convívio diário com os alunos e também nas formações continuadas.

O trabalho docente vem sofrendo interferências da política neoliberal na qual a sociedade moderna está sendo direcionada. Nas palavras de Casagrande e Cainelli:

Do ponto de vista do pertencimento, poderíamos dizer que a sociedade moderna, nos moldes da cultura ocidental, transferiu para a escola e para os profissionais que nela atuam, fundamentalmente aos professores, responsabilidades que antes eram conferidas a outras esferas institucionais reguladoras sugerindo uma ressignificação do papel dessa instituição para a formação do sujeito (CASAGRANDE; CAINELLI, 2015, p. 165). 


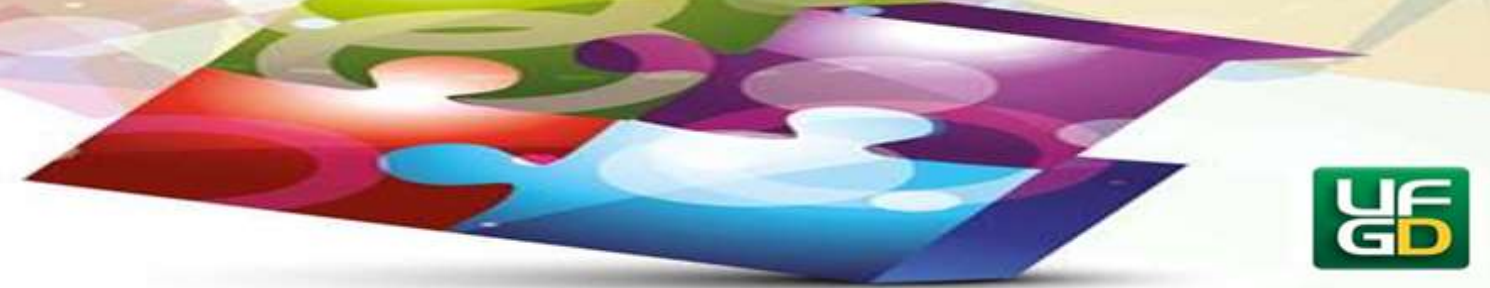

\section{O trabalho docente na contemporaneidade}

Com a advento das Tecnologias de Informação e Comunicação (TIC) na sociedade moderna, a escola precisou se adequar a Cibercultura afetando diretamente no trabalho docente. Muitos professores tentaram resistir a inserção das tecnologias no contexto escolar, no entanto foi inevitável considerando que os próprios alunos fazem uso das tecnologias digitais, sendo que algumas formações continuadas passaram a ser totalmente ou parcialmente na modalidade a distância, ou seja, utilizando recursos tecnológicos. Gerando uma expectativa do uso das TIC na escola e por seus profissionais na mesma velocidade que acontece na sociedade. E sabemos que na educação tudo acontece mais lentamente, pois depende de políticas públicas, infraestrutura e muitas vezes mudanças no currículo. Casagrande e Canielli nos adverte sobre a obsolescência da escola frente as mudanças:

A escola parece despontar como um local de obsolescência frente às mudanças presentes na sociedade; mudanças essas que exercem um poder de sedução e persuasão principalmente sobre crianças e jovens. Estes sujeitos, até por um "status biológico de constante mutação", veem-se mais propensos a se sentir atraídos por tudo que simbolize velocidade, movimento, transitoriedade. As mudanças vêm ocorrendo numa velocidade tal que sentimos dificuldade em processá-las e atribuir-lhes significado (CASAGRANDE; CAINELLI, 2015, p. 174).

A formação inicial e continuada precisa ir ao encontro das práticas docente, proporcionar somente a instrumentalização mecânica não é suficiente para oferecer aos professores maior segurança no uso das mídias como recursos pedagógicos no contexto escolar. A Cibercultura não é simplesmente a troca de um recurso por outro, mas é incorporar as tecnologias digitais como um complemento enriquecedor aos conteúdos curriculares. Ignorar a Cibercultura é uma ingenuidade, pois ela já faz parte do nosso dia a dia e principalmente dos nativos digitais. Ela pode ser uma ferramenta pedagógica importante no processo educativo e na inter-relação professor/aluno (CASAGRANDE; CAINELLI, 2015).

A formação docente é um processo de construção do profissional para o exercício do magistério. Essa formação necessita ser pensada e executada como um direito fundamental que garanta a valorização profissional. Além disso, para Santos (2018, p. 159) a formação "Implica, ao mesmo tempo, compreender os dilemas docentes, o próprio papel do professor, suas relações 
com os alunos, com a arte, com o movimento da cidade, com as políticas dos governos, com as tecnologias (SANTOS, 2018, p. 159).”

Outro desafio contemporâneo é o acesso desenfreado a informação e ao conhecimento. Acesso esse que pode gerar uma maior desigualdade social e intelectual. Linhares e Linhares (2018) nos adverte sobre dois tipos de receptores dos produtos culturais contemporâneos, os receptores ativos que utilizam “[...] os diversos meios de informação e comunicação, inclusive, os ambientes e recursos midiáticos da internet e suas redes sociais [...] para discutir e inquirir a realidade (LINHARES; LINHARES, 2018, p. 248)". E os receptores passivos que não interagem e não realizam a mediação da comunicação. É fundamental uma análise crítica e reflexiva a respeito das informações que circulam nos meios digitais a fim de produzir conhecimentos que vão ao encontro da realidade. Nas palavras de Linhares e Linhares (2018, p. 254):

A abundância de informação gerada e socializada no espaço digital, como em
sites, blogs e redes sociais ao mesmo tempo que potencializa a democratização da
informação, mecanismo cultural de acesso ao saber, pode representar também
escassez de informação que leve ao conhecimento e a conscientização - subsídios
para analisar criticamente a realidade e identificar nela, os processos reguladores
e emancipadores que a constitui retratada no desconhecimento dos direitos,
processos, fenômenos, entraves e contradições que historicamente regem as
relações sociais em todos os espaços de sociabilidade humana, inclusive, no
ciberespaço (LINHARES; LINHARES, 2018, p. 254).

Dentro da temática da Cibercultura vemos que o trabalho docente vem se transformando. Atualmente com a EaD muitos docentes além de sua jornada diária nas escolas ainda trabalham como professores e/ou tutores em cursos oferecidos na modalidade a distância. A flexibilidade quanto aos locais e horários de trabalho, características do trabalho contemporâneo, a EaD tem sido uma opção para melhorar a condição financeira desses profissionais. Todavia Veloso (2018) adverte em seu texto sobre a precarização do trabalho docente na educação a distância. $\mathrm{O}$ autor alerta sobre essa precarização quando diz:

[...] docentes são contratados temporariamente ou em regime parcial, isso quando são, efetivamente, contratados, pois são comuns os profissionais que recebem outros tipos de auxílio que não um salário. Essa flexibilidade, no que diz respeito à contratação, acaba por esfacelar os direitos trabalhistas, estabelecendo uma insegurança e imputando aos trabalhadores a culpa, por exemplo, pelo desemprego (VELOSO, 2018, p. 116). 
A busca por essa ajuda financeira a fim de ter uma renda maior não seria necessária se esses profissionais tivessem salários dignos em sua profissão. Outra questão levantada por Veloso (2018) diz respeito a complexidade do trabalho desempenhado e a quantidade de horas semanais dedicadas às funções na $\mathrm{EaD}$. O autor enfatiza como esse trabalho tem se tornado informal, uma vez que não se tem vínculo trabalhista e nenhum direito trabalhista assegurado.

No texto intitulado "O trabalho docente na América Latina: identidade e profissionalização" de Dalila Andrade Oliveira, a autora discute sobre a complexa identidade e a profissionalização dos professores, que "são em geral funcionários públicos ou empregados de instituições privadas que cada vez mais trabalham submetidos a orientações e controles externos (OLIVEIRA, 2012, p. 31)." Constatamos que a identidade docente não está somente relacionada a construção do ser, mas também do estar na profissão. É uma construção política.

Esses profissionais têm sofrido perdas significativas relacionadas ao desenvolvimento do seu trabalho e isso tem gerado um mal-estar docente. De Souza Dias (2013, p.172) faz uma análise interessante sobre esse assunto:

Os docentes, ao viver o confronto com situações novas, têm sido levados a atribuir novos sentidos à sua atividade de trabalho. No cotidiano escolar eles têm que, cada vez mais, responder à demanda por maior disponibilidade de tempo para o exercício da docência, dedicando-se a novos estudos, ao desenvolvimento de projetos interdisciplinares, aos trabalhos de campo e, ainda, ao planejamento e execução de uma prática mais dinâmica e processual, o que tem desencadeado um processo de (re)trabalho do saber.

Nesse contexto de novas demandas feitas ao trabalho docente, é possível observar uma situação de "mal-estar" e, ainda, de agravamento dos processos de adoecimento desses profissionais. Acreditamos que fatores tais como $o$ distanciamento entre a formação do professor e a realidade socioeconômica e cultural do aluno, as condições objetivas do trabalho, a organização do trabalho no espaço escolar, a relação subjetiva do profissional com o seu trabalho e o relacionamento interpessoal contribuem, de alguma forma, para agravar ainda mais tal quadro de "mal-estar" e de adoecimento (DE SOUZA DIAS, 2013, p. 172).

\section{O trabalho docente do Licenciado em Computação}

O curso de Licenciatura em Computação (LC) foi criado dentro de um contexto histórico que precisa ser compreendido. No Brasil, no início da década de 1980 a cultura tecnológica na Educação Básica surge com a utilização da linguagem LOGO, criada por Seymour Papert, 


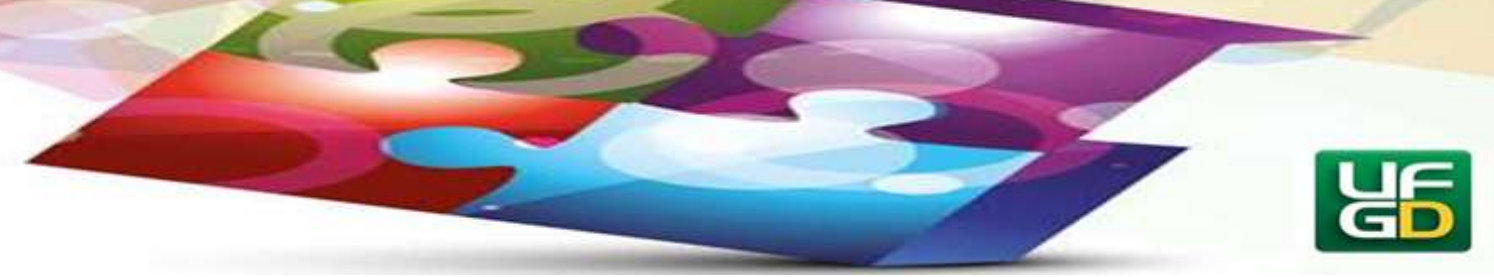

sendo praticamente esquecida com o surgimento dos computadores pessoais e o software de escritório (editor de texto e de imagem, planilha eletrônica) no final dos anos 1980 (VALENTE, 2016). Na década de 1990, mais precisamente em 9 de abril de 1997, é criado pela Portaria ${ }^{\circ}$ 522/MEC o Programa Nacional de Tecnologia Educacional (ProInfo) ${ }^{3}$ com o objetivo de promover o uso da tecnologia como ferramenta de enriquecimento pedagógico no ensino público fundamental e médio. O ProInfo possibilitou a instalação de laboratórios de informática e do acesso à Internet em algumas escolas, com isso "[...] aumentou a necessidade de a comunidade escolar pensar sobre o que fazer com esses equipamentos, como integrar tecnologias à educação e como capacitar seus docentes para uso intencionalmente pedagógico dessas tecnologias" (ZORZO et al., 2017, p.82).

Diante deste cenário, a Sociedade Brasileira de Computação (SBC) por meio da comunidade envolvida com o desenvolvimento de uma cultura tecnológica na educação, destacamos especificamente o Workshop sobre Educação em Computação (WEI) que proporcionou espaços de discussão sobre a inserção das tecnologias na educação. Em 1995, durante o III WEI foi realizado o painel "Informática no Ensino Fundamental" onde "[...] as primeiras sementes para criação do curso LC foram lançadas” (ZORZO et al., 2017, p. 83). O primeiro curso de LC surgiu na Universidade de Brasília (UNB) em 1997.

Em paralelo a esses eventos é sancionada a Lei de Diretrizes e Bases da Educação Brasileira (LDB 9394/96), legislação que regulamenta o sistema educacional (público ou privado) do Brasil (da educação básica ao ensino superior) e a resolução 1/2002 do Conselho Nacional de Educação (CNE) que institui Diretrizes Curriculares Nacionais (DCN) para a Formação de Professores da Educação Básica, em nível superior, curso de licenciatura, de graduação plena criando uma nova estrutura para a formação de professores.

Em 2002, o curso de LC integra as DCN dos Cursos de Graduação em Computação da SBC por meio da criação de um Currículo de Referência dos Cursos de Licenciatura em Computação ${ }^{4}$. Apesar de ser um curso pouco conhecido, com a publicação do artigo de Jeannette M. Wing que discute o pensamento computacional como sendo é uma habilidade

\footnotetext{
${ }^{3}$ Acesso ao ProInfo: http://portal.mec.gov.br/proinfo/proinfo

${ }^{4}$ Acesso ao Currículo de Referência da LC no endereço: http://www.sbc.org.br/documentos-dasbc/summary/131-curriculos-de-referencia/763-curriculo-de-referencia-lic-versao-2002
} 
cognitiva fundamental para todos, não somente para os cientistas da computação (WING, 2006), que pesquisas sobre essa temática começaram a emergir. A discussão sobre o desenvolvimento do pensamento computacional na Educação Básica e a ascensão do uso das tecnologias educacionais vem sendo debatidas no cenário internacional e nacional, evidenciando o curso de Licenciatura em Computação.

No Brasil, ainda não há uma regulamentação propriamente dita, mas há indícios. Nas competências gerais da Base Nacional Comum Curricular - BNCC no item 5 consta:

Utilizar tecnologias digitais de comunicação e informação de forma crítica, significativa, reflexiva e ética nas diversas práticas do cotidiano (incluindo as escolares) ao se comunicar, acessar e disseminar informações, produzir conhecimentos e resolver problemas (BRASIL, 2017, p.18).

E o Plano Nacional de Educação (PNE) 2014-2024 (BRASIL, 2014) prevê metas e estratégias com relação à educação nacional a serem implementadas. Dentre as estratégias traçadas para atingir as metas do plano, podemos destacar: o desenvolvimento de tecnologias educacionais e de inovação das práticas pedagógicas, bem como a seleção e divulgação de tecnologias que sejam capazes de alfabetizar e de favorecer a melhoria do fluxo escolar e a aprendizagem dos estudantes. Podemos perceber o incentivo à construção de recursos tecnológicos que auxiliem na prática pedagógica e favoreçam a aprendizagem de estudantes da educação básica. Conforme o PNE temos:

5.3. selecionar, certificar e divulgar tecnologias educacionais para a alfabetização de crianças, assegurada a diversidade de métodos e propostas pedagógicas, bem como o acompanhamento dos resultados nos sistemas de ensino em que forem aplicadas, devendo ser disponibilizadas, preferencialmente, como recursos educacionais abertos;

5.4. fomentar o desenvolvimento de tecnologias educacionais e de práticas pedagógicas inovadoras que assegurem a alfabetização e favoreçam a melhoria do fluxo escolar e a aprendizagem dos(as) alunos(as), consideradas as diversas abordagens metodológicas e sua efetividade (BRASIL, 2014, p.59).

Tendo um curso de nível superior, logo pensamos em seus caminhos profissionais, sendo assim dentro deste contexto quando visualizamos o trabalho docente do licenciado em Computação logo imaginamos esse sujeito num ambiente escolar. Todavia não há no currículo da Educação Básica disciplinas da área de Computação como temos Matemática, História, Ciências, Geografia, entre outras. Pensando desta maneira surge alguns questionamentos: Onde e como será o desenvolvimento do seu trabalho docente? Como as instituições escolares irão 


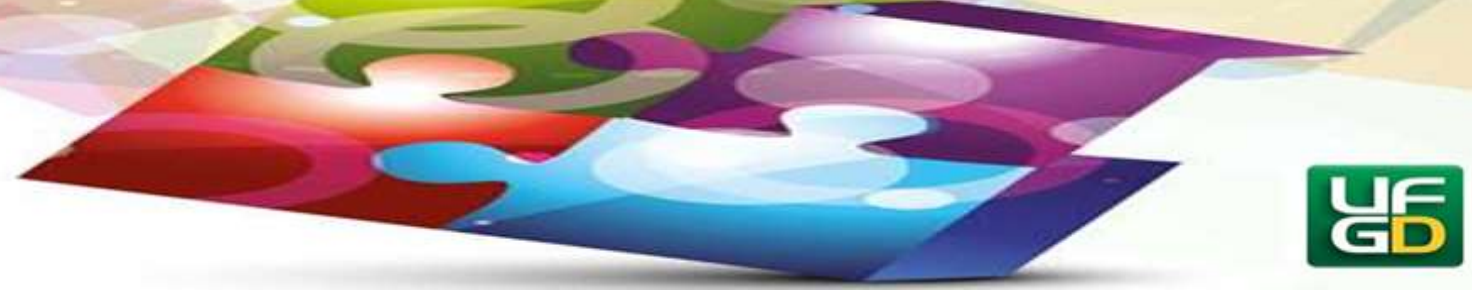

absorver esse profissional? Qual a identidade profissional do licenciado em Computação? Uma vez formado, quais os caminhos profissionais que irá atuar? Se não for exercer a profissão a qual está qualificado que outros caminhos buscarão?

O licenciado em Computação pode atuar em outros espaços que não seja os escolares, contudo sua formação é no exercício da docência criando uma expectativa para o desenvolvimento do trabalho docente em ambientes escolares. Hoje as escolas do Mato Grosso do Sul têm as salas de tecnologia, porém os professores que ali trabalham em sua maioria não possuem uma formação docente inicial como a do licenciado em Computação. A formação inicial destes professores é em outras áreas do conhecimento como Matemática, História, Geografia e outras.

Nos ambientes escolares podemos perceber como é vasto o campo de atuação do licenciado em Computação, exercendo de maneira interdisciplinar/transdisciplinar atividades com as outras áreas de conhecimentos. Dando suporte ou até mesmo desenvolvendo softwares educacionais em conjunto com as demais áreas. Proporcionando aos professores e alunos um ambiente propício para o uso das tecnologias educacionais. Pode gerenciar e desenvolver projetos educacionais por meio da transversalidade envolvendo conceitos e temas a respeito da Cibercultura e a forma como a informação está sendo propagada nos meios digitais. Administrar toda a infraestrutura dos laboratórios de informática existente na escola. Além de produzir materiais didáticos por meio da utilização dos recursos computacionais (BRASIL, 2016).

O desenvolvimento do trabalho docente é um processo amplo que acompanha o professor ao longo de sua vida profissional. No caso do professor cuja formação inicial é em Licenciatura em Computação, é necessário assegurar a esse profissional a possibilidade de desenvolver algumas e/ou todas suas habilidades e competências que durante o processo de formação inicial foram adquiridas. O Estado precisa reconhecer esse profissional que surgiu para atender as demandas de mercado, da globalização e do neoliberalismo e propiciar os espaços para seu desenvolvimento profissional.

\section{Considerações Finais}




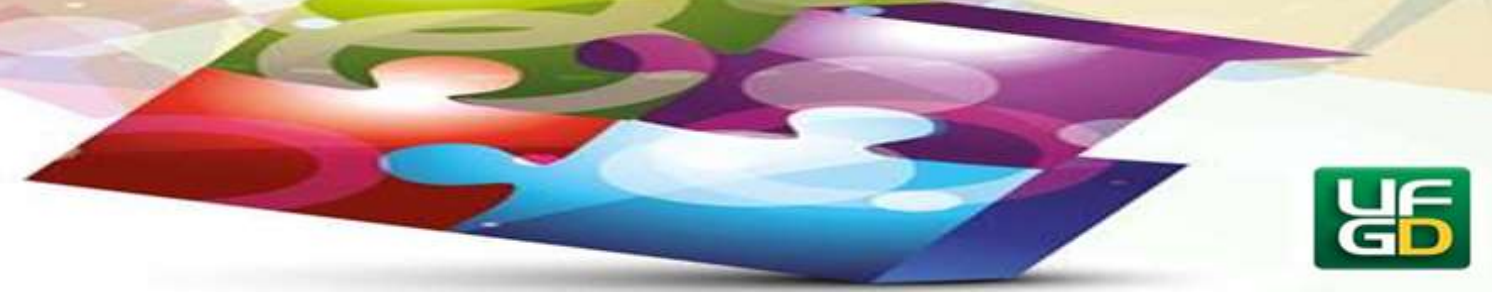

A docência tem sido tema de muitas pesquisas na área da Educação, seja para discutir a crise, seja sobre a prática docente, seja pela avaliação da docência e/ou pela qualidade do ensino. A recorrência desse tema tem motivado muitos pesquisadores, mas não só a docência em si, mas também o trabalho docente e o seu desenvolvimento profissional.

O trabalho docente tem sido analisado no contexto contemporâneo, imerso na Cibercultura e nas informações sem limite: Professores fartos das interferências no desenvolvimento no seu trabalho, sendo controlados por organizações internacionais e por um sistema que só visa o mercado e o capital; Professores que estão em constantes avaliações pela sociedade; Professores que se encontram em um quadro de "mal-estar" e adoecidos por causa das situações que são frequentemente submetidos; e, Professores que sofrem pela desvalorização profissional.

Nesse cenário, encontramos o licenciado em Computação. Um professor com formação inicial, mas sem campo para o desenvolvimento do seu trabalho docente. Um profissional que busca nos ambientes escolares sua identidade profissional ainda sem reconhecimento. Um profissional que ainda é visto simplesmente como um técnico de laboratório com a função de manter os laboratórios funcionando.

\section{Referências}

BRASIL. Ministério da Educação. Plano Nacional de Educação 2014-2024. 2014. Disponível em: <http://www.planalto.gov.br/CCIVIL_03/_Ato20112014/2014/Lei/L13005.htm>. Acesso em 28 out. 2017.

BRASIL. Ministério da Educação. Resolução Nº5, de 16 de novembro de 2016. Disponível em:<http://portal.mec.gov.br/index.php?option=com_docman \&view=download \&alias=52101 -rces005-16-pdf\&category_slug=novembro-2016-pdf\&Itemid=30192>. Acesso em: 18 jul. 2018.

BRASIL. Ministério da Educação. Base Nacional Comum Curricular: Versão final. 2017. Disponível em: 〈http://basenacionalcomum.mec.gov.br/images/BNCC_publicacao.pdf〉. Acesso em 25 out. 2017.

CASAGRANDE, Marilsa Paula; CAINELLI, Marlene. O professor e a escola: mudanças e permanências frente aos desafios da modernidade. Revista NUPEM, v. 7, n. 12, p. 163-181, 


\section{MORIZONTES - REVISTA DE EDUCAÇÃO}

e-ISSN: 2318-1540

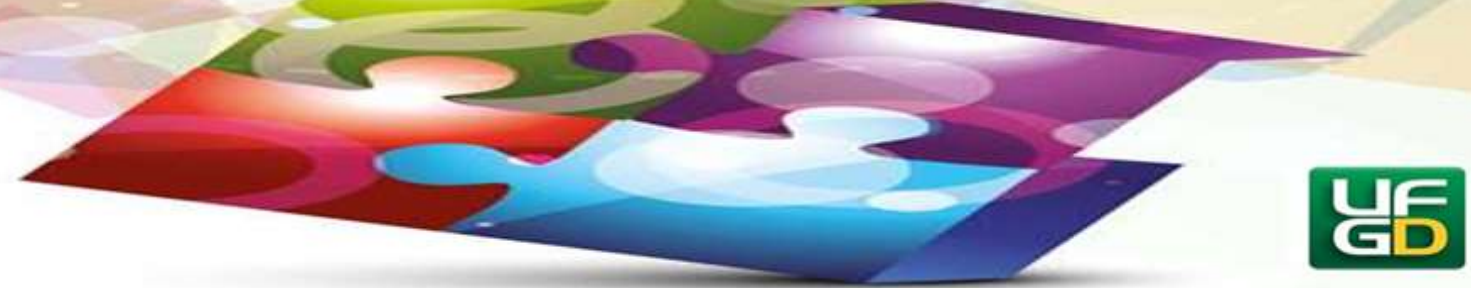

2015. Disponível em

<http://www.fecilcam.br/revista/index.php/nupem/article/viewFile/482/465>. Acesso em 04 set. 2018.

DE SOUZA DIAS, Deise et al. DAS DORES E DELÍCIAS DO TRABALHO DOCENTE: UMA ANÁLISE DO TRABALHO/The pains and the delights of teaching work: a analysis of work. Trabalho \& Educação-ISSN 1516-9537, v. 22, n. 2, p. 169-181, 2013. Disponível em <https://periodicos.ufmg.br/index.php/trabedu/article/view/8942> Acesso em: 30 out. 2018.

DINIZ-PEREIRA, Júlio Emílio. O ovo ou a galinha: a crise da profissão docente e a aparente falta de perspectiva para a educação brasileira. Revista Brasileira de Estudos Pedagógicos, v. 92, n. 230, 2011. Disponível em <http://www.emaberto.inep.gov.br/index.php/rbep/article/view/541>. Acesso em: 14 ago. 2018.

LINHARES, Ronaldo Nunes; LINHARES, Maria Conceição Silva. Educação e Comunicação na sociedade digital: luz e sombras que espelham as vias dicotômicas entre regulação e a emancipação. Educação em Foco, v. 23, n. 1, p. 245-268, 2018.

OLIVEIRA, Dalila Andrade. O trabalho docente na América Latina: identidade e profissionalização. Retratos da escola, v. 2, n. 2/3, 2012. Disponível em $<$ http://retratosdaescola.emnuvens.com.br/rde/article/view/122/225>. Acesso em: 23 out. 2018 .

OLIVEIRA, Dalila Andrade. As políticas de formação e a crise da profissionalização docente: por onde passa a valorização?. Revista Educação em Questão, v. 46, n. 32, 2013. Disponível em <https://periodicos.ufrn.br/educacaoemquestao/article/view/5122/4100>. Acesso em: 14 ago. 2018.

SANTOS, Rosemary. A FORMAÇÃO DE FORMADORES NA CIBERCULTURA E A ATUAÇÃO DOCENTE UNIVERSITÁRIA. Educação em Foco, v. 23, n. 1, p. 153-174, 2018. Disponível em < http://ojs2.ufjf.emnuvens.com.br/edufoco/article/view/19965/10646>. Acesso em: 02 out. 2018.

VALENTE, José Armando. Integração do Pensamento Computacional no currículo da Educação Básica: Diferentes estratégias usadas e questões de formação de professores e avaliação do aluno. Revista e-Curriculum, v. 14, n. 3, 2016. Disponível em: <http://www.redalyc.org/pdf/766/76647706006.pdf>. Acesso em 28 out. 2017.

VEIGA, Ilma Passos Alencastro. Docência como atividade profissional. In: VEIGA, Ilma Passos Alencastro; D’Avila Cristina (Org.). Profissão docente: novos sentidos, novas perspectivas. Campinas, SP: Papirus, 2008. p. 13-21. 


\section{MORIZONTES - REVISTA DE EDUCAÇÃO}

e-ISSN: $2318-1540$

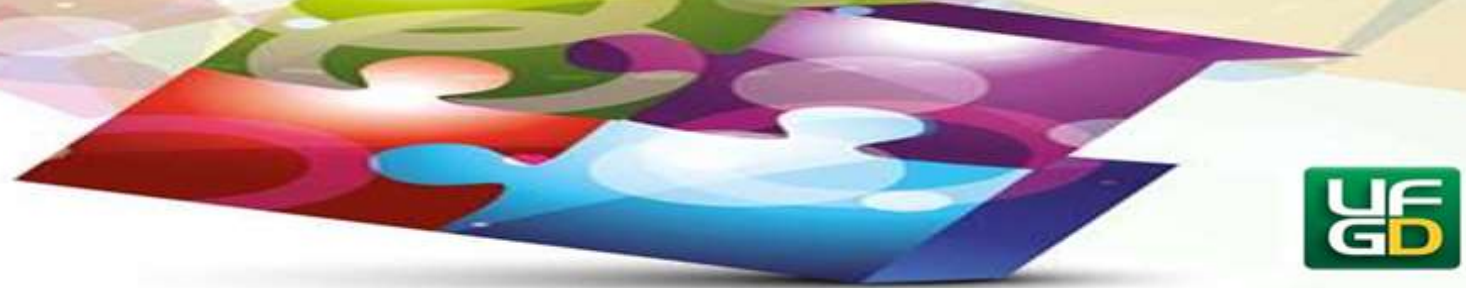

VELOSO, Braian Garrito; MILL, Daniel. Precarização do Trabalho Docente na Educação a Distância: elementos para pensar a valorização da docência virtual. Educaçãa em Foco, v. 23, n. 1, p. 111-132, 2018. Disponível em

<https://educacaoemfoco.ufjf.emnuvens.com.br/edufoco/article/view/3344/158>. Acesso em: 13 fev. 2019.

WING, Jeannette M. Computational thinking. Communications of the ACM, v. 49, n. 3, p. 33-35, 2006.

ZORZO, A. F.; Nunes, D.; Matos, E.; Steinmacher, I.; Leite, J.; Araujo, R. M.; Correia, R.; Martins, S. "Referenciais de Formação para os Cursos de Graduação em Computação". Sociedade Brasileira de Computação (SBC). 153p, 2017. ISBN 978-85-7669-424-3.

Enviado: $30 / 06 / 2020$

Aceito: 31/08/2020 